Research Article

\title{
Determination of Aflatoxins in Feed by HPLC and PCR
}

Areej Zuhair Azeez*, Mrwa Thamer Hindi, Maha Muhamed Khudiar, Adel Saadi AL-Saadi and Noor Ibrahim Khadim

Environment and Water Directorate, Food Contamination Research Center, Ministry of Science and TechnologyEnvironment, Iraq, Baghdad.

*Corresponding author: Areej Zuhari Azeez I Email: tina_iraq2000@yahoo.com

Received: 28 October 2020; Revised: 22 November 2020; Accepted: 24 November 2020; Published: 31 December 2020

\begin{abstract}
The aim of this study is to identify aflatoxin secretion isolates in animal feeds by using HPLC and PCR methods. In this study we collected fourty three samples of animal feed from different sites in Iraq (maize ,soybean ,sunflower grain ,barley grain, wheat). we isolated fungi on potato dextrose agar, Aspergillus flavus fungi was isolated from this samples and identified the enzyme activities were tested for this isolate. The detection and determination for aflatoxin secretion of the isolates were done by using High Performance Liquid Chromatography (HPLC) technique. Twelve isolates shown Aflatoxin B1 secretion. Polymrease chain reaction ( PCR) technique is an alternative method to detect for Aspergillus spp. strains that secret aflatoxin by using specific primers( ITS1) endogenous gene for Aspergillus flavus and (ord, nor) genes for aflatoxin B1 secreation, the PCR technique considered to be an important role for safety and quality in industrial food and feed.
\end{abstract}

Keywords : Aflatoxin, Aspergillus flavus, , HPLC, PCR, Toxicity

\section{INTRODUCTION}

Aspergillus flavus and Aspergillus parasiticus fungi produced the Aflatoxins (AF) are secondary metabolites. At least 17 different forms have been identified and among them Aflatoxins G1, G2, B1 and B2 are considered the most dangerous, showing properties of genotoxicity, carcinogenicity and immune toxicity [1-3]. Aflatoxins are responsible for contamination of various plant-based foods including cereals, oil seeds, fruit ashell, dried fruit, baby food and feed [4]. AFs belong to category B of Annex 1 of (Directive 23/1996/EC) and, as required by [5], for these substances have set a maximum level value allowed in food for direct human consumption of $(2 \mu \mathrm{g} / \mathrm{kg}$ for aflatoxin B1 and $4 \mu \mathrm{g} / \mathrm{kg}$ ) for Total aflatoxins (G1,G2, B1and B2) For animal feed [6], in accordance with [7], establishes for AFB1 a maximum feedstock content of $0.02 \mathrm{mg} / \mathrm{kg}$ and variable limits in the range $0.005-0.02 \mathrm{mg} / \mathrm{kg}$ for products intended for animal feed. Among the numerous methods reported in the literature for the determination of AF in products food (enzyme immunoassays, chromatographic methods with pre-post-column chemical derivatization or online electrochemical derivatization), combined reverse phase separationto the fluorimetric detection with post-column photochemical derivatization.

It is economic and easy to use and ensures high reproducibility of analysis, without the need for control of the derivatization reaction. Furthermore, this analytical method is rapid and 
highly sensitive and allows to quantify separately the different Aflatoxins, requirement indispensable when it is necessary to ascertain the level of AFB1 only, as in the case of food for zoo technical use.

The validation procedure of the analytical method (HPLC) High Performance Liquid Chromatography with derivatization post-column photochemistry for determination of AFB1, AFB2, AFG1 and AFG2 in products food and feed materials [8]. The requirements of the analytical method have been verified through a validation procedure, performed in accordance with the provisions of [9], which allows to integrate the [10] with the European protocols regarding validation, as reported in [11]. The aim of this study is to identify aflatoxin secretion isolates in animal feeds by using HPLC and PCR methods and determinate the concentration of aflatoxin and study the ability of this isolates to enzyme activity [12].

\section{MATERIALS AND METHODS}

\subsection{Solutions}

Methanol, acetonitrile, water for $\mathrm{HPLC}(\mathrm{NaCl}, \mathrm{KCl}$, dibasic sodium phosphate monohydrate, monobasic phosphateof potassium and TWEEN 20® from Sigma - Aldrich (Germany), immunoaffinity columns Afla CLEANTM from LCTech GmbH (Dorfen, Germany).The standard solutions of AFB1, AFB2, AFG1 and AFG2 were purchased from Riedel-deHaën (Sigma-Aldrich, Germany).

\subsection{Equipment}

The equipment used was an Agilent Technologies SL 1200 lc Series (Germany) equipped with a fluorimetric detector (model G1321A) and UVETM online photochemical derivatization device (LC Tech GmbH, Dorfen, Germany).

The chromatographic column chosen was $(150 \times 4.6) \mathrm{mm}$ in size with $(5) \mu \mathrm{m}$ particles. The conditions for chromatography are shown in Table 1 .

Tabel 1. HPLC technique condition for aflatoxin

\begin{tabular}{l|l}
\hline \multicolumn{2}{c}{ Parameter } \\
\hline Mobile Fase & \multicolumn{1}{c}{ Parameter Condtions } \\
Flow & $(1) \mathrm{Ml} / \mathrm{Min}$ \\
Injection Volume & $(20) \mathrm{Ml}$ \\
Colum Temperature & $(40)^{\circ} \mathrm{C}$ \\
Derivatization & Photochemistry: $\Lambda$ Derivatization $(254) \mathrm{Nm}$ \\
Fluorimetric Detection & $\Lambda$ Excitement(365) Nm; $\Lambda$ Emission $(435) \mathrm{Nm}$ \\
\hline
\end{tabular}

\subsection{Collection of samples}

The samples are collected and prepared to testing for aflatoxin and other mycotoxins. Forty three Samples of feed animal collected from different places in Iraq. The samples include (maize, soya bean, sunflower grain, barley grain, wheat) were prepared to analyzed.

\subsection{Aflatoxin extraction}

Aflatoxin were extracted according to [12] method.(mixing sample with solvent (equal volume of chloroform and methanol) shaking and filtration then adding methanol $90 \%$ in separating 
funnel then collect methanol layer and evaporating methanol in water path,washing with chloroform and evaporating finally transfer sample to HPLC test.

\subsection{Screening for enzyme activity}

For screening of differents enzymes (pectinase, cellulase, CMCase, ligninase, xylanase, amylase, protease and lipase), Czapek-Dox agar, malt extract, starch agar, casein agar and PDA were used as described by [13].

\subsection{Molecular detection}

\subsubsection{DNA extraction}

In this study the DNA was extracted by two methods: Wizard Genomic DNA Extraction Kit,by Promega and Manual method according to [14] Fungal extracted DNA was examined by gel electrophoresis using $0.7 \%$ agarose.

\subsubsection{PCR amplification}

PCR amplification was performed using specific primers (Table 2).

Table 2. PCR primers,Sequence and size of amplified product used in PCR

\begin{tabular}{|c|c|c|c|c|}
\hline Gene & $\begin{array}{l}\text { Gene } \\
\text { Description }\end{array}$ & Sequence $\quad\left(5^{\prime}-3^{\prime}\right)$ & $\begin{array}{l}\text { Size of } \\
\text { amplified } \\
\text { product (bp) }\end{array}$ & References \\
\hline \multirow[t]{2}{*}{ ITS1 } & Int1 & CCGAGTTTACAACTCCCAAA & 108 & [15] \\
\hline & Int2 & ACAGAGTTTAGGGGTCCTCT & & \\
\hline ord1 501 & forward & TTAAGGCAGCGGAATACAAG & 610 & [16] \\
\hline ord2 226 & reverse & GACGCCCAAAGCCGAACACAAA & & \\
\hline nor1 & forward & ACCGCTACGCCGGCACTCTCGGCAC & 400 & \\
\hline nor2 & reverse & GTTGGCCGCCAGCTTCGACACTCCG & & {$[17]$} \\
\hline
\end{tabular}

For Aspergillus genus and species (initial denaturation at $94{ }^{\circ} \mathrm{C}$ for $3 \mathrm{~min}$ ), 30 cycles of amplification (denaturation $94^{\circ} \mathrm{C}$ for $30 \mathrm{sec}, 57^{\circ} \mathrm{C}$ for 40 sec., and $72{ }^{\circ} \mathrm{C}$ for $1 \mathrm{~min}$ ) with final reaction volume $25 \mu \mathrm{l}$. For aflatoxins genes multiplex PCR was also carried out with following amplification cycles: denaturation for $5 \mathrm{~min}$ at $94{ }^{\circ} \mathrm{C}$, annealing of the primers for $30 \mathrm{sec}$. at $95^{\circ} \mathrm{C}$ and extension of the primers of $7 \mathrm{~min}$ at $72{ }^{\circ} \mathrm{C}$; 35 cycles with final reaction volume $50 \mu \mathrm{l}$, were performed of amplification using thermal cycler gradient PCR 22331 System (eppendorf).

To detect PCR products, each sample, represented by $5 \mu \mathrm{l}$ of amplicon was subjected to electrophoresis in Agarose gel at 1.5\% (agarose, promega) with using of $4 \mu$ l ethidium bromide at 90 volts for $1 \mathrm{~h}$. To estimate the number of base pairs of fragments standard weight molecular of 100-1500 bp (Amplisize TM Molecular Ruler, Bio-Rad, Hercules, USA) was used.

\section{RESULT AND DISCUSSION}

Animal feed samples were examined for quantification of fungal screening using a potato dextrose agar media, 12 isolates were identified as Aspergillus flavus by microscope according to [18], as seen Figure 1. 


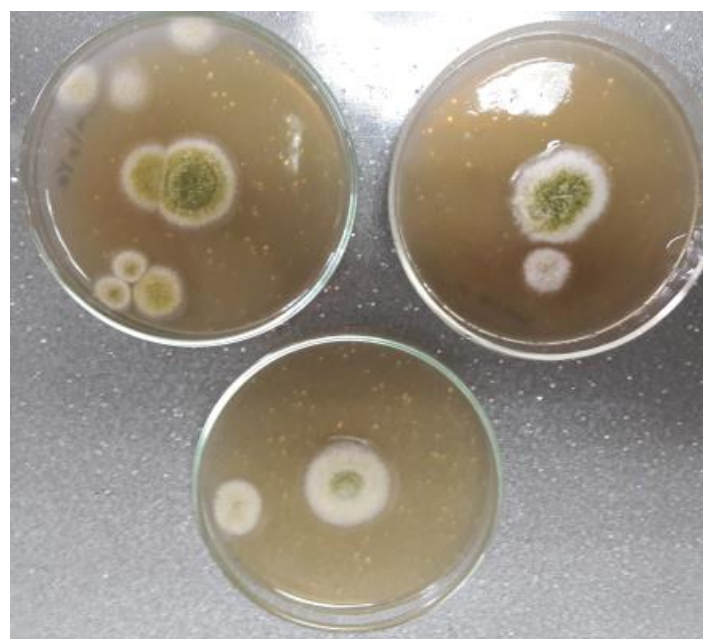

Figure 1. Aspergillus flavus on potato dextrose agar

The isolate were examined on Aspergillus differentiation medium base agar to determination aflatoxin production by production orange zone around colony which are positive for aflatoxin production the zone were measured as mentioned in Table 2 . The petridishes were examined under U.V. light and the colonies were fluoresces as aflatoxin production (Fig.2).

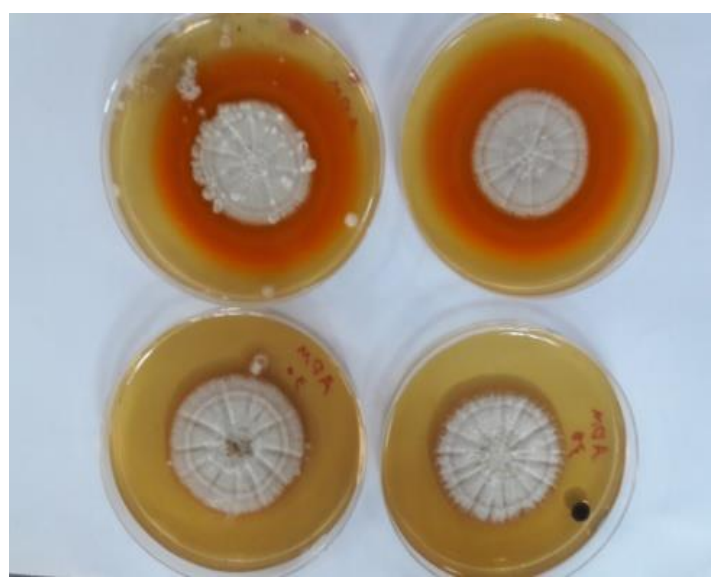

Figure 2 . Aflatoxin detection on Aspergillus differentiation medium base.

Thirty one isolates were positive for some enzyme activity as mentioned below in Table 3 and Figure 3.

Table 3. Enzyme activity screening for Aspergillus flavus

\begin{tabular}{c|cccccccc}
\hline Isolates & $\begin{array}{l}\text { Protease } \\
\mathbf{m m} .\end{array}$ & $\begin{array}{l}\text { Legninase } \\
\mathbf{m m} .\end{array}$ & Amylase & xylonase & $\begin{array}{l}\text { Cellulose } \\
\mathbf{m m} .\end{array}$ & Lipase & CMCase & Pectenase \\
\hline 1 & 13 & 10 & 7 & - & 3 & - & - & 5 \\
2 & 11 & 10 & 5 & - & 3 & - & - & - \\
3 & 9 & 10 & 7 & - & 3 & - & - & 4 \\
4 & 3 & - & 7 & - & 3 & - & - & - \\
5 & 8 & 10 & 7 & - & 3 & - & - & 6 \\
\hline
\end{tabular}




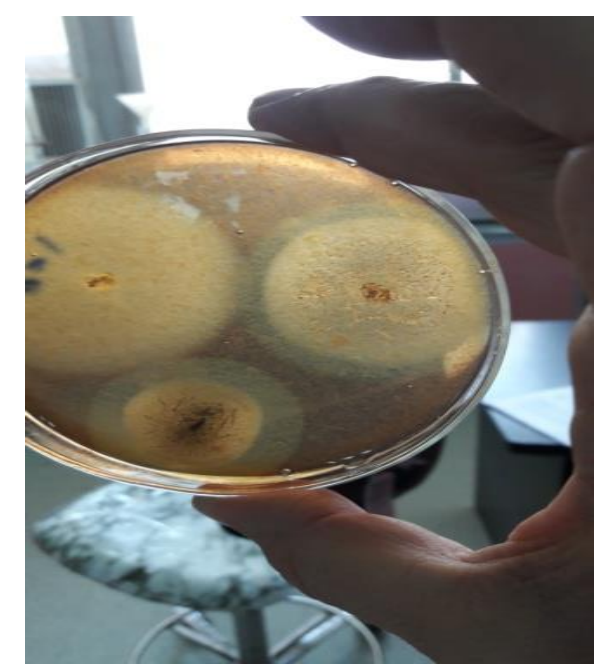

Figure 3. Aspergillus flavus isolates grown on agar to identify enzyme

In this study the diameters of enzyme activity halos were adjusted as to Agar-Plate Assay in to report the enzymatic activity screen[19]. The activity of enzymes by fungi increase with the time, Aspergillus flavus recorded a high protease of all examined enzyme due to the genetic make up [20].

HPLC with fluorescence detection can be used as a quantitative method ofconfirmation for the determination of Aflatoxins, provided that the method requirements meet as indicated in [10]. This legislation identifies the criteria of precision and accuracy to be satisfied and defines, with[9], the performance parameters of the method to be evaluated.The proposed method of analysis has been validated for both feed materials that for food products. The performance criteria, assessed over 2 analytical sessions for the first and on 3 sessions for the second, at 0.5, 1 and 1.5 the maximum allowed limit were results complying with what is defined in [10].

The standard injected with a concentration $0.05 \mathrm{mg} / \mathrm{g}$. The retention time appeared at 5.048 min with a recovery area 23600 Mv.s. The injected sample (aflatoxin) appeared at 5.14 min and the area peak was 2176 Mv.s. The concentration of sample by using B1 aflatoxin standard solution the result is 0.01 ppm (Fig. 4) [21].

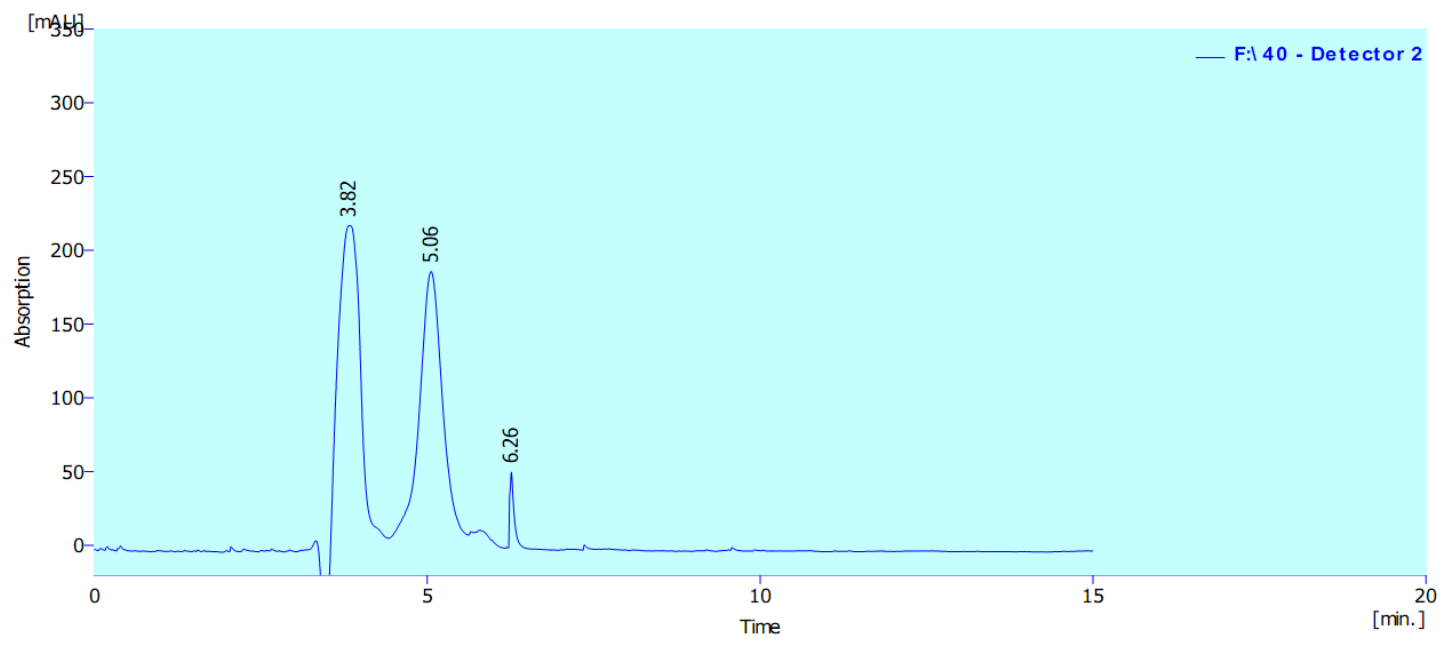

Figure 4. Chromatograms of a standard solution of Aflatoxinsat the total concentration of $2.5 \mu \mathrm{gg} / \mathrm{kg}(\mathrm{A})$ and a fortified almond sample with AFB1 and AFG1 at $2.0 \mu \mathrm{g} / \mathrm{kg}$ and with AFB2 and AFG2 at $0.5 \mu \mathrm{gg} / \mathrm{kg}$ (B). 
The selectivity of the method, assessed by analyzing 10 samples per species (wheat, almonds, pistachios, corn and oats), allowed, in combination with the robustness tests, the application of the analysis method to the matrices indicated above.

That the relative uncertainty values\% for AFB1 (10.1\%) and for Total aflatoxins (13.0\%), guarantee an adequate level of precision for the analysis of confirmation.

The proposed analytical method has been successfully applied for the determination simultaneous Aflatoxins, Ochratoxin A and Fusarium toxins in corn, wheat and barley.The experimental approach developed, based on a double extraction with phosphate buffer and methanol/water (70:30) and purification of the extracts by immune affinity columns multi-antibody, allows the co-extraction of all 11 mycotoxins considered with recoveries acceptable. The characteristics of the method in terms of recoveries and repeatability conform tocriteria established by [10]. The method is also sufficiently sensitive to be applied to the analysis of naturally contaminated cereals and to check in a single one analysis of compliance with the maximum permissible limits established by current legislation [2,3] for Aflatoxins, Ochratoxin A, Deoxynivalenol, Zearalenone and Fumonisine.

The amplification of DNA by ITS primers, which detects a portion of DNA common to all fungi, has the aim of carrying out an initial screening for the presence of DNA fungal in the extracted sample (Fig.5).

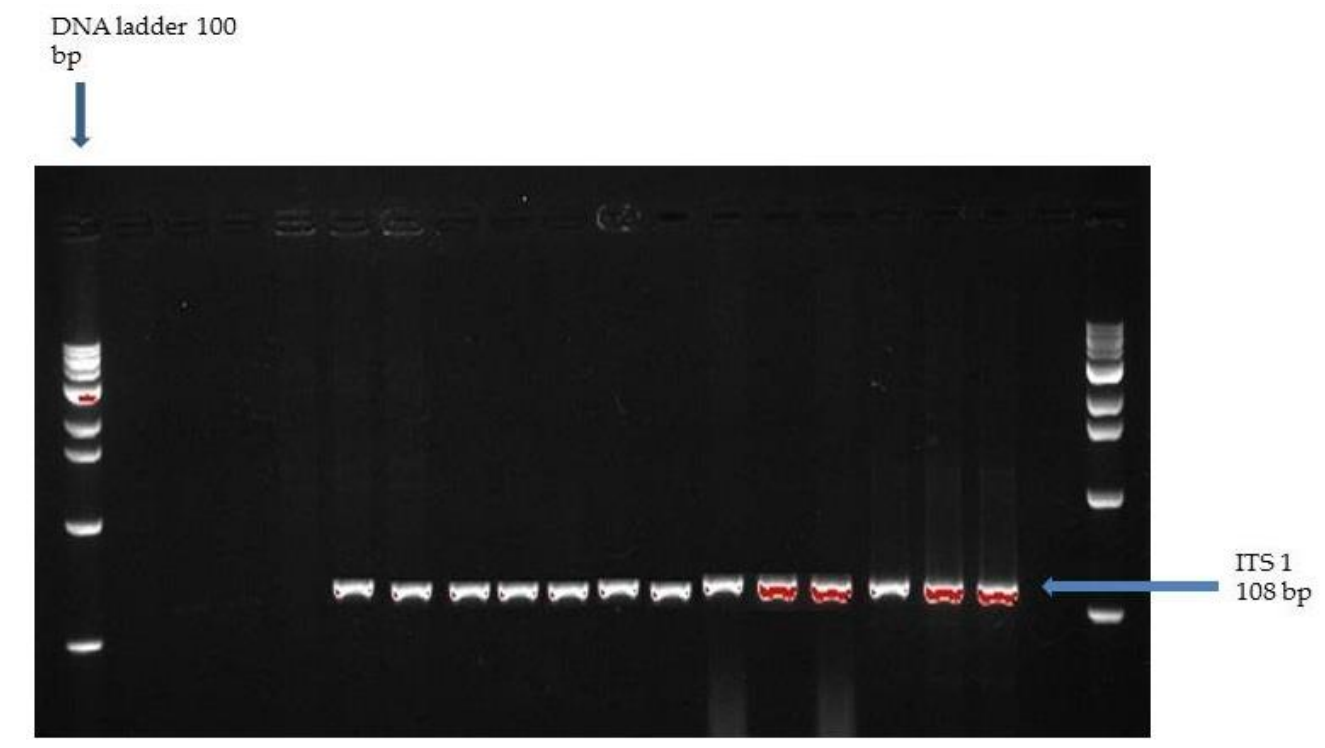

Figure 5. Conventional PCR for ITS-1 gene universal primer for Asp. flavus diagnosis

Different PCR conditions, different concentrations of primers and thermal protocols, using the same Taq-polymerase and the same mix of reaction, without having however, improvements. Since it has been possible to optimize in any way the PCR conditions, it is conceivable that the low amplification efficiency is due to the highly specificity of the primers, which amplify too long a sequence. Therefore it is necessary to revise the design of the ITS primer sequence.

The efficiency values obtained for NOR and ORD are always within acceptable limits. This means that all the reaction conditions have been optimised: the quantity and the quality of the extracted DNA, the concentration of the reagents, the specificity of the primers, the thermal protocol together with the fact that PCR operates with good efficiency, confirms that the assay is well designed and can be used for measurements of type quantity of DNA present in Figure 6. 


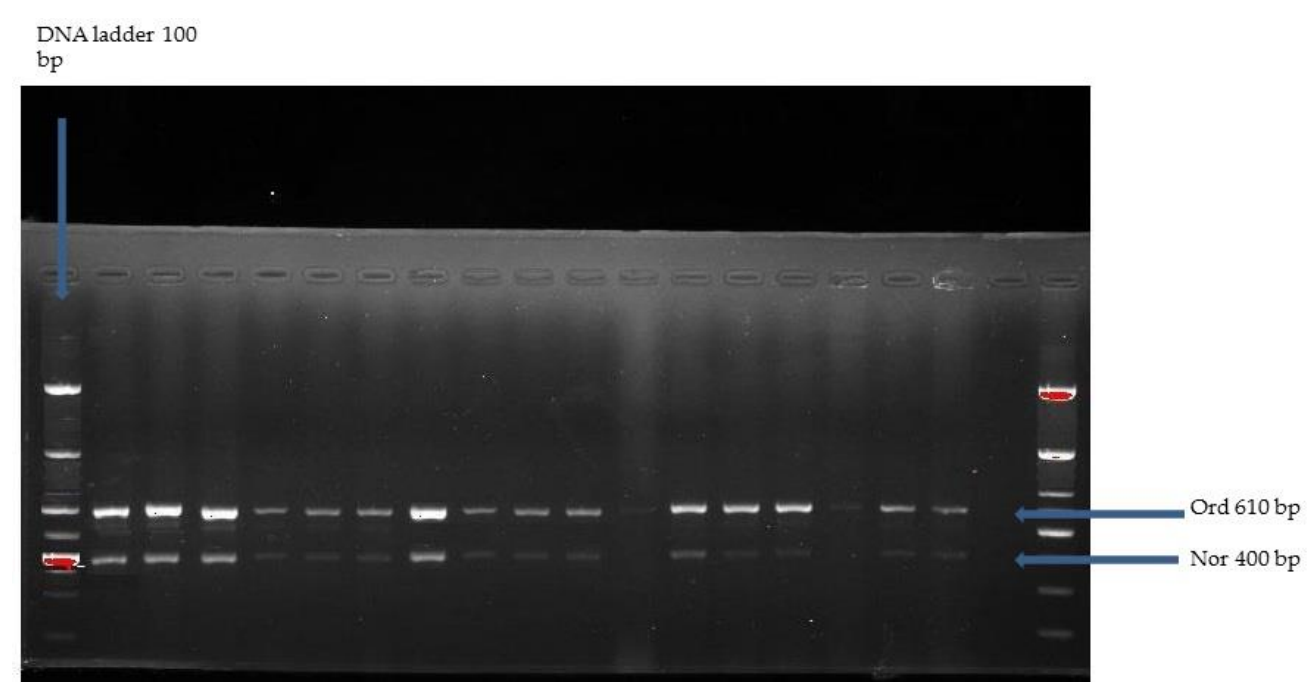

Figure 6. Multiplex PCR for aflatoxin production genes (NOR and ORD)

The protocols developed have shown a good intermediate repeatability (reproducibility PCR), for ITS primers used for amplify the DNA extracted exclusively from Aspergillus and for NOR and ORD primers as shown in Table 1. As already mentioned, the purpose of its primers is to amplify a mixed sample, with DNA belonging to different fungal genera. For this reason, it is necessary to consider all PCR performed on Aspergillus samples. For the other two primers (NOR and ORD) intermediate repeatability values were obtained with the acceptable limit values and therefore very satisfactory.

\section{CONCLUSION}

PCR are: sampling efficiency, associated efficiency to DNA extraction, the number of genomic copies in the target sample, the inhibition of the PCR (primer dimmers, etc.) and the internal variables of the PCR tool (especially a low initial sample concentration). The results presented in the work show that the molecular method, developed in the biology laboratory Ministry of Science and Technology, including the DNA extraction and its amplification, applied to fungal spores, has good performance characteristics.

If you want to apply this method in the future for the characterization and quantification of the mycotoxins, it is certainly necessary to continue the experimentation on Aspergillus spp. but also on other types of conids/spores, in order to obtain a method of DNA extraction applicable to a mixed sample, including many fungal genera.

Acknowledgement: We would like to thank all mycology laboratory staff for the isolation and identification of fungi, also many thank for Saad Sabah Fakhry for his expert advice and encouragement through this paper preparation as well as others Food Contamination Research Center staff for them brilliance in the center.

\section{Conflict of interest: -}

\section{References}

1. Dickens, F. and Jones, H.E. The carcinogenic action of aflatoxin after its subcutaneous injection in the rat.Br J Cancer. 1963, 17:691-8.

2. Bullerman, L.B. Significance of mycotoxins to food safety and human health. J Food Prot, 1979, 42:65-86. 
3. Harwig J, Munro IC. Mycotoxins of possible importance in diseases of Canadian farm animals. Canadian Veterinary Journal. 1975, 16:125-41.

4. Eaton, D.L. and Groopman, J.D. The toxicology of aflatoxins. San Diego (CA): Academic Press, 1994.

5. European Union. Commission Regulation (EC) No. 1881/2006 of 19 December 2006 defining the maximum levels of certain contaminants in food products. OJ L364 / 5, 20 December 2006, updated on 23 July 2008.

6. Italy. Legislative Decree 10 May 2004, n. 149. Implementation of directives 2001/102 / EC, 2002/32 / EC, 2003/57 / EC and 2003/100 / EC, relating to undesirable substances and products in animal feed. Official Gazette - General Series n. 139, June 16, 2004.

7. European Union. Directive 2003/100 / EC of the commission of 31 October 2003 amending Annex I of Directive 2002/32 / EC of the European Parliament and of the Council on undesirable substances in animal nutrition. GUCE L285, 1 November 2003.

8. Muscarella, M., Iammarino M., Nardiello D., Magro, S.and Palermo, C. Validation of a confirmatory analytical method for the determination of aflatoxins B1, B2, G1 and G2 in foods and feed materials by HPLC with on-line photochemical derivatization and fluorescence detection. Food Addit Contame, 2009, 26:1402.

9. European Union. Regulation (EC) 882/2004 of the European Parliament and of the Council of 29 April 2004 on official controls aimed at verifying compliance with the legislation on feed and food and animal health and welfare regulations. OJ L 191, 30 April 2004.

10. European Union. Commission Regulation (EC) No. 401/2006 of 23 February 2006 concerning the methods of sampling and analysis for the official control of the levels of mycotoxins in food products. GUCE L70 / 12, 9 March 2006.

11. European Union. Commission Decision 2002/657 / EEC of 12 August 2002 which implements Council Directive 96/23 / EEC on the performance of analytical methods and interpretation of results. GUCE L221, August 17, 2002.

12. AOAC Official Method 2000.08. Aflatoxin M1 in liquid milk, immunoaffinity column by liquid chromatography. Natural Toxins-chapter 49 (pp. 45-47). Official Methods of Analysis of AOAC International, 18th edition, AOAC International. Gaithersburg, Maryland 20877-2417, USA, 2005.

13. Anustrup, W.Jr. and Katchalski, L. Production and isolation and economics of extracellular enzyme Bionge 2: Enzyme Technology, Ed. By Katzir, Glosten, L. Academic Press, New York, San Francisco, 1979.

14. Gael, L. and Philippe, S. Rapid methods for nucleic acids extraction from Petri dish-grown mycelia. Curr Genet, 1994, 25:122-123. DOI: 10.1007/BF00309536

15. Grimm, C. and Giesen, R. A PCR-ELISA for the detection of potential fumonisin producing Fusarium species. Lett. Appl. Microbial, 1998, 25:456-462.

16. Sweeney, M.J. and Dobson, A.D.W. Mycotoxin production by Aspergillus, Fusarium and Pencillium species Int. J . Food Microbial, 1998, 43:141-158. DOI: 10.1016/s0168-1605(98)00112-3

17. Giesen, R. Multiplex Polymerase Chain Reaction for the detection of potential Aflatoxin Sterigmatocystin producing Fungi. system. Appl. Microbial, 1996, 19:388-392.

18. Wilson D.M., Mubatanhema W.and Jurjevic, Z. Biology and ecology of mycotoxigenic Aspergillus species as related to economic and health concerns. Adv. Exp. Med. Biol, 2002, 504: 3-17. DOI: 10.1007/978-1-46150629-4_2

19. Gastón, E. O., Diego G. N., María, C. P. M, Matías, N.R., Martín, B. and Edgardo, A. A Comparative Study of New Aspergillus Strains for Proteolytic Enzymes Production by Solid State Fermentation, Enzyme Res, 2016, vol. 2016, Article ID 3016149, 11 pages, 2016. https://doi.org/10.1155/2016/3016149. 
20. Oyeleke, S.B.; Egwim, E.C. and Auta, S.H. Screening of Aspergillus flavus and Aspergillus fumigatus strains for extracellular protease enzyme production. Journal of Microbiology and Antimicrobials, 2010, 7: 83-87.

(C) 2020 by the authors. Submitted for possible open access publication under the terms and conditions of the Creative Commons Attribution (CC BY) license (http://creativecommons.org/licenses/by/4.0/). 